\title{
Stressed liver and muscle call on adipocytes with FGF21
}

\section{Yongde Luo* and Wallace L. McKeehan}

IBT Proteomics and Nanotechnology Laboratory, Center for Cancer and Stem Cell Biology, Institute of Biosciences and Technology, Texas A\&M Health Science Center, Houston, TX, USA

\section{Edited by:}

Gary Sweeney, Institut Pasteur, South

Korea, York University, Canada

\section{Reviewed by:}

Minho Shong, Research Center for

Endocrine and Metabolic Diseases,

South Korea

Stephan Wueest, University

Children's Hospital Zurich, Switzerland

${ }^{*}$ Correspondence:

Yongde Luo, IBT Proteomics and Nanotechnology Laboratory, Center for Cancer and Stem Cell Biology,

Institute of Biosciences and

Technology, Texas A\&M Health

Science Center, 2121 W. Holcombe

BIvd., Houston, TX 77030-3303, USA

e-mail:yluo@ibt.tamhsc.edu
Fibroblast growth factor 21 (FGF21) is an emerging regulator of local and systemic metabolic homeostasis. Treatment with pharmacological levels of FGF21 alleviates obesity and associated metabolic diseases including diabetes. However, beyond anti-obesogenic effects, the normal roles and underlying mechanisms of FGF21 as an endocrine hormone remain unclear. A recent wave of studies has revealed that FGF21 is a stressinduced endocrine factor in liver, muscle, and other tissues that targets adipose tissue and adipocytes through the FGFR1-betaKlotho complex. Adipose tissues and adipocytes within diverse tissues respond with metabolites and adipokine signals that affect functions of body tissues systemically and cells within the local microenvironment adjacent to adipocytes. Normally this is to prevent impaired tissue-specific function and damage to diverse tissues secreting FGF21 in response to chronic stress. Therefore, diverse stressed tissues and the adipose tissue and adipocytes constitute a beneficial endocrine and paracrine communication network through FGF21. Here we attempt to unify these developments with beneficial pharmacological effects of FGF21 on obesity in respect to inter-organ stress communication and mechanisms.

\section{INTRODUCTION}

\section{ENDOCRINE FGFS AND THE ROLE OF FGF21}

Since the debut in 2005 (1), fibroblast growth factor 21 (FGF21) has been of growing interest due to its dramatic beneficial effects at pharmacological levels on weight reduction and alleviation of obesity, diabetes, and fatty liver disease $(2,3)$. These effects include promoting clearance of systemic glucose and lipids (cholesterol, fatty acids, and triacylglycerides) and enhancing insulin sensitivity, adiponectin action, mitochondrial function, thermogenesis, and energy expenditure $(1,2,4)$. Unlike most of the FGF family members that require extracellular heparan sulfate proteoglycan and act locally via autocrine and paracrine mechanisms, FGF21 as a member of the endocrine FGF19 subfamily travels through the circulation to sites distal from its origin and acts predominantly as an endocrine hormone (5). Instead of heparan sulfate proteoglycans, the activity of FGF2 1 is determined by a transmembrane co-receptor betaKlotho (KLB) that is present as a binary complex with FGF receptor tyrosine kinases (FGFR) in several endocrine and metabolic tissues. This allows selective action of circulating FGF21 on the target tissues expressing FGFR1-KLB complex without affecting those expressing FGFR1 alone.

Basal serum levels of FGF21 vary widely among individuals and are generally low in pure strains of laboratory mice (6). Deficiency or overexpression of FGF21 does elicit alterations in metabolic gene expression in the liver and adipose tissue, but without dramatic metabolic phenotypes under normal physiological conditions $(7,8)$. In contrast, pharmacologic applications of FGF21 in obese and diabetic animals suggest a wide range of effects across multiple tissues with marked anti-obesogenic and anti-diabetic efficacy $(1,2,4,9)$. However, beyond such drastic pharmacological effects in the obese, the possible functions of FGF21 as a circulating hormone in organ-specific physiopathologies have remained elusive.

\section{FGF21 AS AN INDUCIBLE STRESS HORMONE FROM MULTIPLE TISSUES}

Studies in mice indicate that FGF21 is inducible and the liver is a major source of circulating FGF21 $(9,10)$. Parallel to serum levels, expression of hepatic FGF21 under normal physiological conditions is low; however, during prolonged fasting and starvation, both hepatic and serum FGF21 become dramatically elevated. This triggered early proposals that the physiological role of FGF21 was a starvation hormone that regulates ketogenesis essential for brain function during severe carbohydrate deficits $(9,10)$. A growing number of studies with animals and patients indicate that FGF21 is induced, in addition to starvation and obesity, by diverse pathogenic conditions such as liver injury, viral infection, chemical insult, specific nutritional deficiency, the hepatic regenerative response as well as liver diseases as hepatosteatosis, steatohepatitis, cirrhosis, and liver cancer (11-17). The common feature of all these conditions is that they impose stress on the liver that compromises its role in maintenance of organism metabolic homeostasis. Therefore, hepatic FGF21 appears to be an inducible hepatic stress signal.

In contrast to the liver that is a switching station for processing metabolites in support of other organs and tissues and the adipose tissue that serves as a storage depot of energy and metabolic precursor of lipids, muscle is a major fuel consumer. To meet high aerobic catabolic demands for ATP, muscle secretes myokines that call on liver and adipose tissue to supply adequate fuel. Consistent with this concept, several recent studies indicate that FGF21 is induced in skeletal, heart, and gastrocnemius muscle under conditions that cause local and systemic metabolic stress (18-25). These 
include patients with a mitochondrial respiratory chain deficiency in myocytes and mice defective in muscular autophagy/mitophagy $(20,26,27)$. FGF21 may be an insulin and AKT-regulated myokine and its expression is associated with chronic muscular hyperinsulinemia or lipodystrophy $(22,23)$. Increases in muscle contraction such as in chronic exercise also upregulates muscular FGF21 production $(21,25)$. Fe-S cluster-deficient muscles in patients showed a dramatic upregulation of FGF21 expression and elevated levels of circulating FGF21 (20). This indicates that muscle stressed by perturbations in mitochondrial energy metabolism responds by increasing the secretion of FGF21 into the circulation.

In addition to liver and muscle, it has been suggested that FGF21 is inducible and secreted into the circulation in other tissues and organs under stress conditions. Brown adipose tissue (BAT) may be a source of FGF21 in response to cold stress and fetal-toneonatal transition $(28,29)$. White adipose tissue (WAT) has been reported to secrete FGF21 under some conditions (30). However, a physiological contribution of stress-induced adipocyte FGF21 to systemic FGF21, or an autocrine activity of FGF21 within WAT, BAT, and adipocytes in the local microenvironment, remains to be validated. Since stressed pancreas has been reported to be a beneficiary of external FGF21 $(31,32)$, it is also a candidate for induction of FGF21 as a signal for aid from adipose tissue.

These studies suggests that the activation of FGF21 in liver, muscle, and other tissues is a response of these tissues and organs to stress triggered by external challenge and internal cellular pathogenesis that lead to defects in metabolic homeostasis. In support of this notion, several nuclear receptors and transcription factors that are involved in metabolic stress responses regulate FGF21 expression. These include PPAR $\alpha / \gamma$, RAR, ChREBP, SREBP1c, LXR, STAT3/5, p53, and ATF4 (9, 16, 26, 33-39). The question is why these organs when under stress use FGF21 as a systemic alarm signal.

\section{ADIPOCYTES ARE THE TARGET OF FGF21 FROM MULTIPLE TISSUES}

Several recent studies using direct ablation of FGFR1 or KLB in adipocytes, administration of activating antibody targeting specifically the FGFR1-KLB complex, or induction of dysfunctional adipose tissue (40-44) provide compelling evidence that adipose tissue and adipocyte FGFR1-KLB is the primary tissue and molecular target of inter-organ messenger FGF21, respectively. Although many types of tissues and cells express FGFR1 alone, mature adipocytes co-express FGFR1 with KLB, the transmembrane coreceptor for FGF21 and FGF19 (45). Similar to the general ablation of FGF21 (8), adipocyte-specific FGFR1 ablation resulted in few overt changes in adipogenesis, adipose secretory function, and systemic metabolic status under normal physiological conditions (46). However, under the metabolic stress of starvation, the absence of adipocyte FGFR1 caused increased adipocyte lipolysis. This occurred concurrently with elevation of serum triglycerides and fatty acids while indirectly causing an increase in hepatic lipogenesis and steatosis (46). This indicated that under such conditions adipocyte FGFR1 signaling dampens adipocyte lipolysis while concurrently dampening hepatic steatosis. Paradoxically yet most dramatically, the adipocyte FGFR1 deficiency abrogated nearly all the anti-obese and anti-diabetic effects elicited by pharmacological levels of FGF21 $(40,43)$. The alleviation of muscular abnormalities caused by muscular mitochondrial energy dysfunction and defects in autophagy/mitophagy appear to be in large part due to effects of induced FGF21 on adipose tissue $(26,27)$. Adaptation to cold stress may be aided by elevated levels of FGF21 that acts on BAT to promote pro-thermogenic mitochondrial activity $(28,29)$.

Taken together, these studies indicate that stress messenger FGF21 and adipose FGFR1-KLB team up to respond to stress caused by a wide range of metabolic abnormalities and pathogenesis. The stress-responsive communication mediated by extraadipose FGF21 and adipocyte FGFR1-KLB occurs predominantly between adipose tissue and at least two tissues whose roles in metabolism are quite different, but when stressed have major consequences on the organism: (1) liver whose role is to maintain lipid, carbohydrate, and organism metabolic homeostasis through synthesis, degradation, and temporary storage; and (2) muscle which is a major fuel consumer predominantly powered by the oxidation of fats and carbohydrates (Figure 1). Although so far liver and muscle have received the most attention as two major organs that send out FGF21 as a stress signal, other organs may utilize the same mechanism to call on adipocytes in major fat depots (WAT and BAT) or in the microenvironment of diverse tissues. Within the microenvironment of tissues that contains ectopic or interspersed adipose tissue or adipocytes, such as the breast, bone marrow, and the perirenal and epicardial regions, FGF21 may serve to modify adipocyte signaling that affects parenchymal cell functions through a paracrine mechanism. Within stressed adipose tissues which are predominantly adipocytes, both paracrine and autocrine mechanisms may be at play. The ultimate effect of the communication initiated by the FGF21 messenger is to elicit beneficial signals from adipocytes that aid in reduction of the effects of stress and prevention of tissue-specific damage and pathologies resulting from prolonged stress.

\section{THE ROLE OF ADIPOSE TISSUE IN THE FGF21 STRESS RESPONSE}

As a first responder to the SOS message carried by FGF21, how do adipocytes through FGF21-mediated activation of FGFR1-KLB aid stressed tissues and in particular liver and muscle? In addition to as a reservoir of energy, adipose tissue is an endocrine organ capable of systemic signaling through its lipid metabolites and adipokines $(47,48)$. A number of effects of FGF21 on adipose tissue adipocytes have been reported. These include the induction of expression of nuclear receptors and coactivators, diverse enzymes and their cytoplasmic regulators involved in pathways for glucose, lipid, and energy metabolism, and the broad changes in systemic and local tissue metabolic substrates and control pathways $(1,2,4$, 9, 40, 43).

Two major effects of FGF21 directly on adipose tissue stand out that may contribute to relief of metabolic stress on liver and muscle. Activation of the adipocyte FGFR1-KLB complex modulates the rate of adipocyte lipolysis and fatty acid oxidation that indirectly relieves hepatocyte steatosis or muscular lipid overload. Upregulation of expression of genes involved in fatty acid oxidation, browning of white fat and thermogenesis is also thought to collectively contribute to the anti-obesogenic effects $(1,29,40,49)$ in the obese. In contrast, activation of the adipocyte FGFR1-KLB complex during starvation dampens the rate of adipocyte lipolysis, 


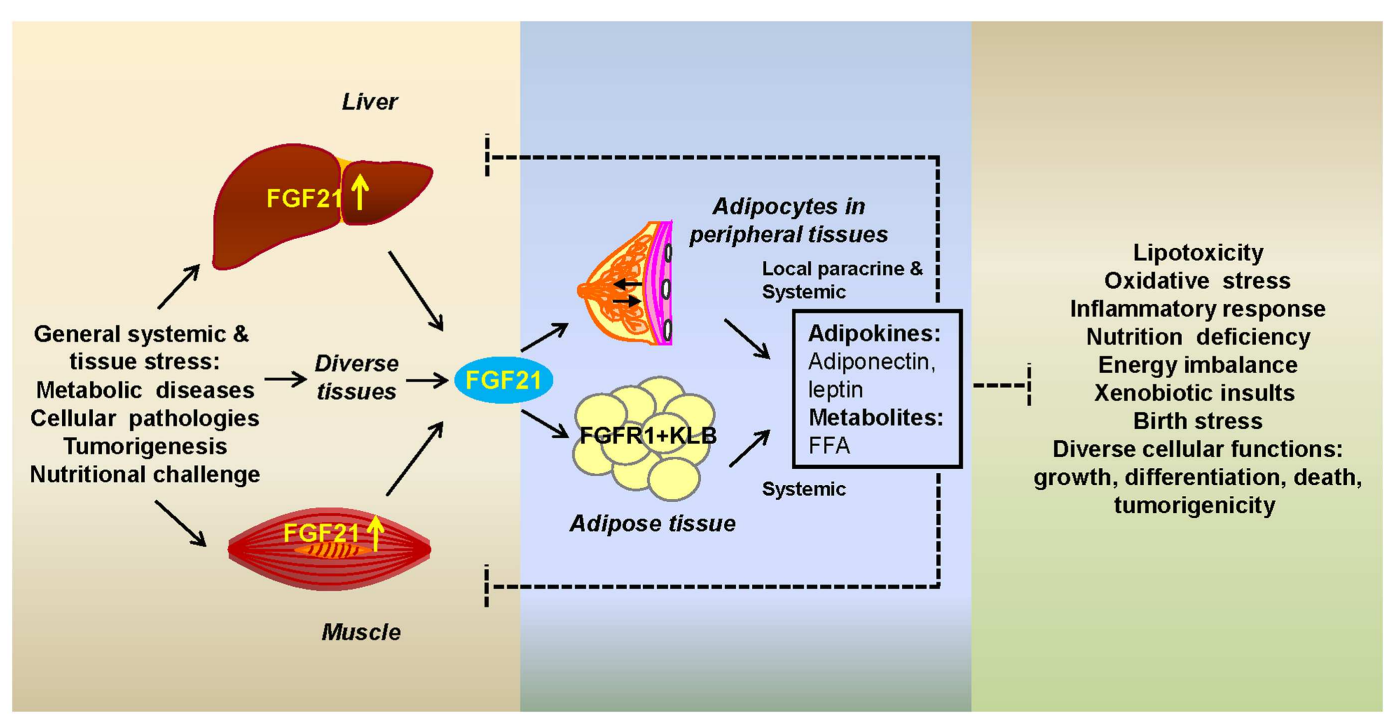

FIGURE 1 | Fibroblast growth factor 21 as a stress hormone acting via a tissue-adipocyte communication axis. Stressed tissues through induction of FGF21 (left box) alert adipocytes by activating the adipocyte FGFR1-KLB complex (center box). Adipocytes respond with secretory metabolic products and adipokines that alleviate tissue-specific stress through modification of cellular pathways whose alterations (right box) are a potentially destructive result of systemic or internal cellular stress (left box). Systemic FGF21 acts on adipocytes in major adipose depots or in the microenvironment of peripheral tissues. Breast is shown as an example of the latter. FGF21-induced adipocyte secretory products, such as adiponectin, leptin, and free fatty acids (FFAs), act both systemically or in the local microenvironment (center box) to affect stressed organs or parenchymal cells, respectively. which may help to extend energy usage. Secondly, recent studies show that FGF21 regulates the endocrine function of adipocytes including the secretion of adipokines that act on diverse tissues throughout the body. Notably the adipokine adiponectin is upregulated and leptin downregulated by FGF21. They appear to mediate many of the systemic and local effects of FGF21 (50, 51). Reduction of effects of a lipotoxic environment and oxidative stress is a common feature of adiponectin in liver, muscle, heart, kidney, pancreas, and endothelium (52). Thus, both the regulation of fatty acid metabolism and modifications of adipokine profile by FGF21 are favorable for the relief of liver's steatotic burden that, when extreme and chronic, causes irreversible hepatic damage (Figure 1). Similarly, these FGF21-induced adipocyte responses are favorable for reduction of lipid overload and lipotoxicity in stressed or diseased muscle and possibly other tissues when autophagy/mitophagy, the mitochondria-ER-Golgi network or homeostasis in insulin function and glucose, lipid, and energy metabolic networks is compromised $(34,53)$.

Are adipocytes via the FGFR1-KLB partnership the primary or even specific target of systemic or local FGF21 signal observed in diverse body tissues? FGF21-stimulated changes in systemic metabolites and adipokines whose receptors are distributed widely have potential to indirectly affect practically all body tissues. Moreover, adipocytes that are characterized by expression of FGFR1KLB and present in the microenvironment of most, if not all, tissues have potential to affect functions of adjacent tissues via FGF21-controlled paracrine products in the microenvironment. A careful dissection of both FGFR isotypes and KLB and signals elicited by the partnership in parenchymal and adipocytes of diverse organs that show a response to systemic FGF21 is required to clarify whether non-adipocyte cells constitute additional direct targets for FGF21. It has been suggested that FGF21 may signal directly in hepatocytes (54), pancreatic islet beta cells $(31,32)$, and cells in the suprachiasmatic nucleus of the hypothalamus and the dorsal vagal complex of the hindbrain $(55,56)$.

\section{CONCLUSION AND FUTURE PERSPECTIVE}

Since the discovery of the regulatory function of FGF21 in metabolism in 2005, studies have focused on the dramatic systemic pharmacological effects and clinical potential of FGF21 in alleviation of obesity and diabetes. These have obscured its general role as a stress hormone in organ-specific physiopathologies with adipose tissue as its tissue target and adipocyte FGFR1-KLB as its molecular target. The adipocyte FGFR1-KLB complex accounts for the weight reduction and anti-diabetic effects of pharmacological FGF21 (40-44). It also likely accounts for the stress-reducing metabolic effects of FGF21 in tissues undergoing a wide range of conditions causing systemic metabolic as well as local tissue and cellular stress. Induced FGF21 expression may be of utility as a biomarker for these conditions. In addition to obesity and its associated metabolic syndromes, pharmacological levels of FGF21 may be of therapeutic benefit for chronic tissue-specific stress-related diseases.

One important question is whether the treatment of metabolic abnormalities accompanying obesity and diabetes and the relief of stress in diverse tissues occur through the same or overlapping adipocyte signals controlled by FGF21 (Table 1). The uncoupling of lipolysis and lipogenesis by FGF21-FGFR1KLB directly in adipocytes and indirectly in hepatocytes together with FGF21-stimulated "browning" of fat and thermogenesis have 


\section{Table 1 | Outstanding questions}

How do different stress conditions commonly induce FGF21 expression?

Is FGF21 of biomarker value for tissue stress?

Do the roles of FGF21 in the stress response and treatment of obesity occur through the same mechanisms?

Do tissues/organs other than liver and muscle also utilize FGF21 as a stress signal?

What is the full spectrum of FGF21-controlled adipocyte signals (metabolites and adipokines) that contribute to alleviation of stress?

How does FGF21 direct KLB-FGFR1 kinase signaling to control adipose tissue function instead of mitogenesis?

been suggested to create a state of futile cycling and enhanced energy expenditure that causes overall reduction of body weight and systemic lipids in the obese $(1,29,40,46,49)$. Under the life-threatening stress of prolonged starvation, this same FGF21FGFR1-KLB mediated uncoupling of overall lipid and carbohydrate metabolism may serve to stretch out lipid reserves for brain fuels to preserve consciousness and reduce neural stress for as long as possible until feeding resumes $(9,46)$. FGF21-elicited adipocyte signals appear to commonly alleviate the extent of hepatic steatosis under the opposite metabolic extremes of obesity and starvation, and the muscular metabolic stress associated with autophagic defects and mitochondrial respiratory dysfunction.

Adipokines have emerged as FGF21-induced endocrine signals that also communicate back to stressed tissues. The upregulation of adiponectin currently is in the spotlight $(40,50,51)$ although the role of the full spectrum of FGF21-controlled adipokines deserves investigation (Table 1). The many facets of the roles of FGF21 as a stress hormone that recruits the aid of adipose tissue adipocytes and its ramifications for stress-related diseases promise to be a broad and fruitful field of future study.

In addition to the tissue-specific responses to FGF21stimulated adipocyte signals that alter metabolism to reduce tissue stress, the mechanisms that control the induction of FGF21 in specific tissues in crisis also requires clarification (Table 1). Multiple transcription factors including nuclear receptors have been implicated in control of FGF21 expression in different tissues. Some of them are involved in the intrinsic cellular stress-responsive pathways, such as the SREBP1c and ATF4 in the ER stress response that are associated with the Golgi, peroxisome $(53,57)$, and mitochondria and involved in lipid, energy, and glucose metabolism. Future studies may reveal novel tissue-specific FGF21-mediated stress response pathways and mechanisms.

The overarching canonical role of members of the diverse FGF superfamily in the adult is coordination of tissue homeostasis through autocrine and paracrine growth-promoting signaling controlled by matrix heparan sulfate. With the loss of affinity for heparan sulfate and gain of selectivity for the FGFR1-KLB complex that predominates in mature adipocytes, FGF21 has evolved as an inter-organ stress signal to adipocytes for negative regulation of systemic and cellular metabolic stress. This concept may also apply to evolution of other endocrine FGFs referred to as the FGF19 subfamily. The inter-organ crosstalk between ileal FGF19 and liver FGFR4-KLB is a negative regulatory mechanism of postprandial bile acid levels serving to prevent stress and damage resulting from exposure to prolonged and elevated levels of bile acids (58). Similarly, the negative regulation of mineral re-absorption levels signaled by the crosstalk between bone FGF23 and kidney FGFR1-KL (59) may limit potential stress and damage from mineral overload. The effects of the FGF19 subfamily are pleiotropic and complex on both local tissue and organism levels. Detailed dissection of the action of each endocrine FGF in interorgan or cross-tissue communication and stress relief promises to be a novel conceptual base for pursuit of complete understanding of the biology of endocrine FGFs.

\section{ACKNOWLEDGMENTS}

This work was supported by the Susan Komen Breast Cancer, the John S. Dunn Research Foundations, US Public Health Service grant DK56338 (Texas Medical Center Digestive Diseases Center), and a Research Enhancement Grant from Texas A\&M University Health Science Center.

\section{REFERENCES}

1. Kharitonenkov A, Shiyanova TL, Koester A, Ford AM, Micanovic R, Galbreath EJ, et al. FGF-21 as a novel metabolic regulator. J Clin Invest (2005) 115:1627-35. doi:10.1172/JCI23606

2. Kharitonenkov A, Wroblewski VJ, Koester A, Chen YF, Clutinger CK, Tigno XT, et al. The metabolic state of diabetic monkeys is regulated by fibroblast growth factor-21. Endocrinology (2007) 148:774-81. doi:10.1210/en.2006-1168

3. Gaich G, Chien JY, Fu H, Glass LC, Deeg MA, Holland WL, et al. The effects of LY2405319, an FGF21 analog, in obese human subjects with type 2 diabetes. Cell Metab (2013) 18:333-40. doi:10.1016/j.cmet.2013.08.005

4. Xu J, Lloyd DJ, Hale C, Stanislaus S, Chen M, Sivits G, et al. Fibroblast growth factor 21 reverses hepatic steatosis, increases energy expenditure, and improves insulin sensitivity in diet-induced obese mice. Diabetes (2009) 58:250-9. doi: $10.2337 / \mathrm{db} 08-0392$

5. Beenken A, Mohammadi M. The FGF family: biology, pathophysiology and therapy. Nat Rev Drug Discov (2009) 8:235-53. doi:10.1038/nrd2792

6. Angelin B, Larsson TE, Rudling M. Circulating fibroblast growth factors as metabolic regulators - a critical appraisal. Cell Metab (2012) 16:693-705. doi:10.1016/j.cmet.2012.11.001

7. Badman MK, Koester A, Flier JS, Kharitonenkov A, Maratos-Flier E. Fibroblast growth factor 21-deficient mice demonstrate impaired adaptation to ketosis. Endocrinology (2009) 150:4931-40. doi:10.1210/en.2009-0532

8. Hotta Y, Nakamura H, Konishi M, Murata Y, Takagi H, Matsumura S, et al. Fibroblast growth factor 21 regulates lipolysis in white adipose tissue but is not required for ketogenesis and triglyceride clearance in liver. Endocrinology (2009) 150:4625-33. doi:10.1210/en.2009-0119

9. Inagaki T, Dutchak P, Zhao G, Ding X, Gautron L, Parameswara V, et al. Endocrine regulation of the fasting response by PPARalpha-mediated induction of fibroblast growth factor 21. Cell Metab (2007) 5:415-25. doi:10.1016/j. cmet.2007.05.003

10. Badman MK, Pissios P, Kennedy AR, Koukos G, Flier JS, Maratos-Flier E. Hepatic fibroblast growth factor 21 is regulated by PPARalpha and is a key mediator of hepatic lipid metabolism in ketotic states. Cell Metab (2007) 5:426-37. doi:10.1016/j.cmet.2007.05.002

11. Dasarathy S, Yang Y, McCullough AJ, Marczewski S, Bennett C, Kalhan SC. Elevated hepatic fatty acid oxidation, high plasma fibroblast growth factor 21, and 
fasting bile acids in nonalcoholic steatohepatitis. Eur J Gastroenterol Hepatol (2012) 23:382-8. doi:10.1097/MEG.0b013e328345c8c7

12. Domingo P, Gallego-Escuredo JM, Domingo JC, Gutierrez Mdel M, Mateo MG, Fernandez I, et al. Serum FGF21 levels are elevated in association with lipodystrophy, insulin resistance and biomarkers of liver injury in HIV-1-infected patients. AIDS (2010) 24:2629-37. doi:10.1097/QAD.0b013e3283400088

13. Dushay J, Chui PC, Gopalakrishnan GS, Varela-Rey M, Crawley M, Fisher FM, et al. Increased fibroblast growth factor 21 in obesity and nonalcoholic fatty liver disease. Gastroenterology (2010) 139:456-63. doi:10.1053/j.gastro.2010.04.054

14. Li H, Fang Q, Gao F, Fan J, Zhou J, Wang X, et al. Fibroblast growth factor 21 levels are increased in nonalcoholic fatty liver disease patients and are correlated with hepatic triglyceride. J Hepatol (2010) 53:934-40. doi:10.1016/j.jhep.2010.05.018

15. Zhang X, Yeung DC, Karpisek M, Stejskal D, Zhou ZG, Liu F, et al. Serum FGF21 levels are increased in obesity and are independently associated with the metabolic syndrome in humans. Diabetes (2008) 57:1246-53. doi:10.2337/db07-1476

16. Yang $\mathrm{C}, \mathrm{Lu} \mathrm{W}$, Lin T, You P, Ye M, Huang Y, et al. Activation of Liver FGF21 in hepatocarcinogenesis and during hepatic stress. BMC Gastroenterol (2013) 13:67. doi:10.1186/1471-230X-13-67

17. Yilmaz Y, Eren F, Yonal O, Kurt R, Aktas B, Celikel CA, et al. Increased serum FGF21 levels in patients with nonalcoholic fatty liver disease. Eur J Clin Invest (2010) 40:887-92. doi:10.1111/j.1365-2362.2010.02338.x

18. Benetti E, Mastrocola R, Rogazzo M, Chiazza F, Aragno M, Fantozzi R, et al. High sugar intake and development of skeletal muscle insulin resistance and inflammation in mice: a protective role for PPAR-delta agonism. Mediators Inflamm (2013) 2013:509502. doi:10.1155/2013/509502

19. Chavez AO, Molina-Carrion M, Abdul-Ghani MA, Folli F, Defronzo RA, Tripathy D. Circulating fibroblast growth factor- 21 is elevated in impaired glucose tolerance and type 2 diabetes and correlates with muscle and hepatic insulin resistance. Diabetes Care (2009) 32:1542-6. doi:10.2337/dc09-0684

20. Crooks DR, Natarajan TG, Jeong SY, Chen C, Park SY, Huang H, et al. Elevated FGF21 secretion, PGC-1alpha and ketogenic enzyme expression are hallmarks of iron-sulfur cluster depletion in human skeletal muscle. Hum Mol Genet (2013). doi:10.1093/hmg/ddt393. [Epub ahead of print].

21. Cuevas-Ramos D, Almeda-Valdes P, Meza-Arana CE, Brito-Cordova G, GomezPerez FJ, Mehta R, et al. Exercise increases serum fibroblast growth factor 21 (FGF21) levels. PLoS One (2012) 7:e38022. doi:10.1371/journal.pone.0038022

22. Hojman P, Pedersen M, Nielsen AR, Krogh-Madsen R, Yfanti C, Akerstrom T, et al. Fibroblast growth factor- 21 is induced in human skeletal muscles by hyperinsulinemia. Diabetes (2009) 58:2797-801. doi:10.2337/db09-0713

23. Izumiya Y, Bina HA, Ouchi N, Akasaki Y, Kharitonenkov A, Walsh K. FGF21 is an Akt-regulated myokine. FEBS Lett (2008) 582:3805-10. doi:10.1016/j.febslet. 2008.10.021

24. Lindegaard B, Hvid T, Grondahl T, Frosig C, Gerstoft J, Hojman P, et al. Expression of fibroblast growth factor-21 in muscle is associated with lipodystrophy, insulin resistance and lipid disturbances in patients with HIV. PLoS One (2013) 8:e55632. doi:10.1371/journal.pone.0055632

25. Yang SJ, Hong HC, Choi HY, Yoo HJ, Cho GJ, Hwang TG, et al. Effects of a three-month combined exercise programme on fibroblast growth factor 21 and fetuin-A levels and arterial stiffness in obese women. Clin Endocrinol (Oxf) (2011) 75:464-9. doi:10.1111/j.1365-2265.2011.04078.x

26. Kim KH, Jeong YT, Oh H, Kim SH, Cho JM, Kim YN, et al. Autophagy deficiency leads to protection from obesity and insulin resistance by inducing Fgf21 as a mitokine. Nat Med (2013) 19:83-92. doi:10.1038/nm.3014

27. Suomalainen A, Elo JM, Pietilainen KH, Hakonen AH, Sevastianova K, Korpela $\mathrm{M}$, et al. FGF-21 as a biomarker for muscle-manifesting mitochondrial respiratory chain deficiencies: a diagnostic study. Lancet Neurol (2011) 10:806-18. doi:10.1016/S1474-4422(11)70155-7

28. Hondares E, Iglesias R, Giralt A, Gonzalez FJ, Giralt M, Mampel T, et al. Thermogenic activation induces FGF2 1 expression and release in brown adipose tissue. J Biol Chem (2011) 286(15):12983-90. doi:10.1074/jbc.M110.215889

29. Hondares E, Rosell M, Gonzalez FJ, Giralt M, Iglesias R, Villarroya F. Hepatic FGF21 expression is induced at birth via PPARalpha in response to milk intake and contributes to thermogenic activation of neonatal brown fat. Cell Metab (2010) 11:206-12. doi:10.1016/j.cmet.2010.02.001

30. Oishi K, Konishi M, Murata Y, Itoh N. Time-imposed daily restricted feeding induces rhythmic expression of Fgf21 in white adipose tissue of mice. Biochem Biophys Res Commun (2011) 412:396-400. doi:10.1016/j.bbrc.2011.07.125
31. Johnson CL, Weston JY, Chadi SA, Fazio EN, Huff MW, Kharitonenkov A, et al. Fibroblast growth factor 21 reduces the severity of cerulein-induced pancreatitis in mice. Gastroenterology (2009) 137:1795-804. doi:10.1053/j.gastro.2009. 07.064

32. Wente W, Efanov AM, Brenner M, Kharitonenkov A, Koster A, Sandusky GE, et al. Fibroblast growth factor-21 improves pancreatic beta-cell function and survival by activation of extracellular signal-regulated kinase $1 / 2$ and Akt signaling pathways. Diabetes (2006) 55:2470-8. doi:10.2337/db05-1435

33. De Sousa-Coelho AL, Marrero PF, Haro D. Activating transcription factor 4dependent induction of FGF21 during amino acid deprivation. Biochem J (2012) 443:165-71. doi:10.1042/BJ20111748

34. Schaap FG, Kremer AE, Lamers WH, Jansen PL, Gaemers IC. Fibroblast growth factor 21 is induced by endoplasmic reticulum stress. Biochimie (2013) 95:692-9. doi:10.1016/j.biochi.2012.10.019

35. Li Y, Wong K, Walsh K, Gao B, Zang M. Retinoic acid receptor beta stimulates hepatic induction of fibroblast growth factor 21 to promote fatty acid oxidation and control whole-body energy homeostasis in mice. J Biol Chem (2013) 288:10490-504. doi:10.1074/jbc.M112.429852

36. Uebanso T, Taketani Y, Yamamoto H, Amo K, Tanaka S, Arai H, et al. Liver X receptor negatively regulates fibroblast growth factor 21 in the fatty liver induced by cholesterol-enriched diet. J Nutr Biochem (2012) 23:785-90. doi:10.1016/j. jnutbio.2011.03.023

37. Yu J, Zhao L, Wang A, Eleswarapu S, Ge X, Chen D, et al. Growth hormone stimulates transcription of the fibroblast growth factor 21 gene in the liver through the signal transducer and activator of transcription 5. Endocrinology (2012) 153:750-8. doi:10.1210/en.2011-1591

38. Zhang Y, Lei T, Huang JF, Wang SB, Zhou LL, Yang ZQ, et al. The link between fibroblast growth factor 21 and sterol regulatory element binding protein 1c during lipogenesis in hepatocytes. Mol Cell Endocrinol (2011) 342:41-7. doi:10.1016/j.mce.2011.05.003

39. Iizuka K, Takeda J, Horikawa Y. Glucose induces FGF21 mRNA expression through ChREBP activation in rat hepatocytes. FEBS Lett (2009) 583:2882-6. doi:10.1016/j.febslet.2009.07.053

40. Adams AC, Coskun T, Cheng CC, Gimeno RE, Luo Y, Kharitonenkov A. The breadth of FGF21's metabolic actions are governed by FGFR1 in adipose tissue. Mol Metab (2012) 2:31-7. doi:10.1016/j.molmet.2012.08.007

41. Ding X, Boney-Montoya J, Owen BM, Bookout AL, Coate KC, Mangelsdorf DJ, et al. betaKlotho is required for fibroblast growth factor 21 effects on growth and metabolism. Cell Metab (2012) 16:387-93. doi:10.1016/j.cmet.2012.08.002

42. Wu AL, Kolumam G, Stawicki S, Chen Y, Li J, Zavala-Solorio J, et al. Amelioration of type 2 diabetes by antibody-mediated activation of fibroblast growth factor receptor 1. Sci Transl Med (2011) 3:113ra26. doi:10.1126/scitranslmed.3002669

43. Foltz IN, Hu S, King C, Wu X, Yang C, Wang W, et al. Treating diabetes and obesity with an FGF21-mimetic antibody activating the betaKlotho/FGFR1c receptor complex. Sci Transl Med (2012) 4:162ra53. doi:10.1126/scitranslmed.3004690

44. Veniant MM, Hale C, Helmering J, Chen MM, Stanislaus S, Busby J, et al. FGF21 promotes metabolic homeostasis via white adipose and leptin in mice. PLoS One (2012) 7:e40164. doi:10.1371/journal.pone.0040164

45. Yang C, Jin C, Li X, Wang F, McKeehan WL, Luo Y. Differential specificity of endocrine FGF19 and FGF21 to FGFR1 and FGFR4 in complex with KLB. PLoS One (2012) 7:e33870. doi:10.1371/journal.pone.0033870

46. Yang C, Wang C, Ye M, Jin C, He W, Wang F, et al. Control of lipid metabolism by adipocyte FGFR1-mediated adipohepatic communication during hepatic stress. Nutr Metab (Lond) (2012) 9:94. doi:10.1186/1743-7075-9-94

47. Galic S, Oakhill JS, Steinberg GR. Adipose tissue as an endocrine organ. Mol Cell Endocrinol (2010) 316:129-39. doi:10.1016/j.mce.2009.08.018

48. Scherer PE. Adipose tissue: from lipid storage compartment to endocrine organ. Diabetes (2006) 55:1537-45. doi:10.2337/db06-0263

49. Fisher FM, Kleiner S, Douris N, Fox EC, Mepani RJ, Verdeguer F, et al. FGF21 regulates PGC-1alpha and browning of white adipose tissues in adaptive thermogenesis. Genes Dev (2012) 26:271-81. doi:10.1101/gad.177857.111

50. Holland WL, Adams AC, Brozinick JT, Bui HH, Miyauchi Y, Kusminski CM, et al. An FGF21-adiponectin-ceramide axis controls energy expenditure and insulin action in mice. Cell Metab (2013) 17:790-7. doi:10.1016/j.cmet.2013.03.019

51. Lin Z, Tian H, Lam KS, Lin S, Hoo RC, Konishi M, et al. Adiponectin mediates the metabolic effects of FGF21 on glucose homeostasis and insulin sensitivity in mice. Cell Metab (2013) 17:779-89. doi:10.1016/j.cmet.2013.04.005 
52. Shetty S, Kusminski CM, Scherer PE. Adiponectin in health and disease: evaluation of adiponectin-targeted drug development strategies. Trends Pharmacol Sci (2009) 30:234-9. doi:10.1016/j.tips.2009.02.004

53. Huang J, Jia Y, Fu T, Viswakarma N, Bai L, Rao MS, et al. Sustained activation of PPARalpha by endogenous ligands increases hepatic fatty acid oxidation and prevents obesity in ob/ob mice. FASEB J (2012) 26:628-38. doi:10.1096/fj.11-194019

54. Fisher FM, Estall JL, Adams AC, Antonellis PJ, Bina HA, Flier JS, et al. Integrated regulation of hepatic metabolism by fibroblast growth factor 21 (FGF21) in vivo. Endocrinology (2011) 152:2996-3004. doi:10.1210/en.2011-0281

55. Bookout AL, de Groot MH, Owen BM, Lee S, Gautron L, Lawrence HL, et al. FGF21 regulates metabolism and circadian behavior by acting on the nervous system. Nat Med (2013) 19:1147-52. doi:10.1038/nm.3249

56. Owen BM, Bookout AL, Ding X, Lin VY, Atkin SD, Gautron L, et al. FGF21 contributes to neuroendocrine control of female reproduction. Nat Med (2013) 19:1153-6. doi:10.1038/nm.3250

57. Peeters A, Swinnen JV, Van Veldhoven PP, Baes M. Hepatosteatosis in peroxisome deficient liver despite increased beta-oxidation capacity and impaired lipogenesis. Biochimie (2011) 93:1828-38. doi:10.1016/j.biochi.2011. 06.034

58. Inagaki T, Choi M, Moschetta A, Peng L, Cummins CL, McDonald JG, et al. Fibroblast growth factor 15 functions as an enterohepatic signal to regulate bile acid homeostasis. Cell Metab (2005) 2:217-25. doi:10.1016/j.cmet. 2005.09.001

59. Urakawa I, Yamazaki Y, Shimada T, Iijima K, Hasegawa H, Okawa K, et al. Klotho converts canonical FGF receptor into a specific receptor for FGF23. Nature (2006) 444:770-4. doi:10.1038/nature05315

Conflict of Interest Statement: The authors declare that the research was conducted in the absence of any commercial or financial relationships that could be construed as a potential conflict of interest.

Received: 26 September 2013; accepted: 04 December 2013; published online: 18 December 2013.

Citation: Luo Y and McKeehan WL (2013) Stressed liver and muscle call on adipocytes with FGF21. Front. Endocrinol. 4:194. doi: 10.3389/fendo.2013.00194

This article was submitted to Cellular Endocrinology, a section of the journal Frontiers in Endocrinology.

Copyright (c) 2013 Luo and McKeehan. This is an open-access article distributed under the terms of the Creative Commons Attribution License (CC BY). The use, distribution or reproduction in other forums is permitted, provided the original author (s) or licensor are credited and that the original publication in this journal is cited, in accordance with accepted academic practice. No use, distribution or reproduction is permitted which does not comply with these terms. 